\title{
补图的连通 度
}

\author{
李慰萱 \\ (浙江宁波硫酸厂工人)
}

我们构造了一组图,以证明下列的定理.

定理 1 若 $p$ 和 $d$ 为满足 $p-2>d>1$ 的整数, $p d$ 为偶数, 则存在一个有 $p$ 个点的 图 $G$, 它是 $d$ 度正则的, 且

$$
\begin{aligned}
& \kappa(G)=\lambda(G)=\operatorname{deg} G=d, \\
& \kappa(\bar{G})=\lambda(\bar{G})=\operatorname{deg} \bar{G}=p-1-d . \\
& \quad \text { 取 } \\
& d= \begin{cases}{\left[\frac{p-1}{2}\right]} & \text { 若 } p \equiv 0,1,2(\bmod 4), \\
\frac{p-3}{2} & \text { 若 } p \equiv 3(\bmod 4),\end{cases}
\end{aligned}
$$

就可由定理 1 推得下列 Y. Alavi, J. Mitchem ${ }^{[1]}$ 和 G. Chartrand ${ }^{[2]}$ 在 1970 年纽约第一次图论 会议上提出, 而未得到解决的命题:

定理 2 对任何自然数 $p \neq 4$, 存在一个 有 $p$ 个点的图 $G$, 使 $G$ 与其补图 $\bar{G}$ 的连通度 的积

$$
= \begin{cases}\kappa(G) \cdot \kappa(\bar{G}) & \\ {\left[\frac{p-1}{2}\right]\left\{\frac{p-1}{2}\right\}} & \text { 若 } p \equiv 0,1,2(\bmod 4), \\ \left(\frac{p-3}{2}\right)\left(\frac{p+1}{2}\right) & \text { 若 } p \equiv 3(\bmod 4) .\end{cases}
$$

用 $\bar{K}_{m}^{(i)}$ 记 $m$ 阶全不连通图. 它的点集记 作 $V_{i}=\left\{v_{i 1}, v_{i 2}, \cdots, v_{i m}\right\}$. 设 $1 \leqslant r \leqslant m$ ， 定义下列记号:

$\{v\}-r-\bar{K}_{m}^{(i)}$ 记 $v$ 与一切 $v_{i j}(1 \leqslant j \leqslant r)$ 邻接. $\bar{K}_{m^{2}}^{\left(i_{1}\right)} \stackrel{r}{\longrightarrow} \bar{K}_{m^{2}}^{\left(i_{2}\right)}$ 记 $V_{i_{1}}$ 与 $V_{i_{2}}$ 之间联以线集

$$
\begin{gathered}
\left\{\left(v_{i_{1} i_{1}}, v_{i_{2} j_{2}}\right) ; j_{1}=1,2, \cdots, m,\right. \\
\left.j_{2}-j_{1} \equiv 1,2, \cdots, r(\bmod m)\right\} .
\end{gathered}
$$

(不标明箭头时指可以任意规定一个方向). $\bar{K}_{m}^{\left(i_{1}\right)}{ }_{r}--\bar{K}_{m}^{\left(i_{2}\right)}$ 记 $V_{i_{1}}$ 与 $V_{i_{2}}$ 之间联以线集

$$
\left\{\left(v_{i_{1} i}, v_{i_{2} j}\right) ; j=r+1, r+2, \cdots, m\right\} \text {. }
$$

用以证明定理 1 的图(显然只要在 $2<d$ $\leqslant \frac{p-1}{2}$ 的情形下定义即可. $d=2$ 时为 $p$ 阶圈 $C_{p}, d>\frac{p-1}{2}$ 时为上述图的补图) 可. 以分三种情形用上列简记法表示如下:

$$
\begin{gathered}
p=2 m, 2<d \leqslant m-1 . G \text { 为 } \\
\bar{K}_{m}^{(1)}-d-\bar{K}_{m}^{(2)} .
\end{gathered}
$$

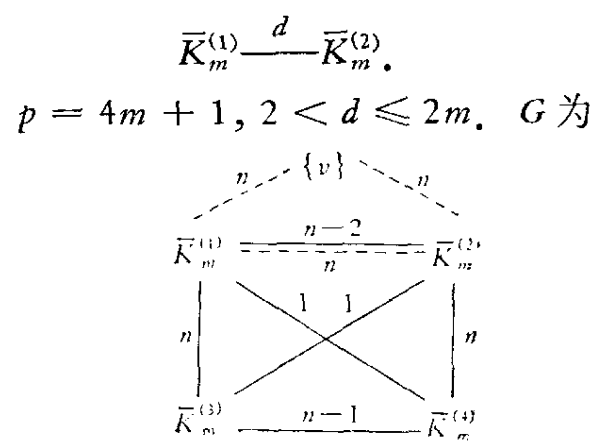

$$
p=4 m+3,2<d \leqslant 2 m(d \text { 为偶数, 故 }
$$

不为 $2 m+1), G$ 为

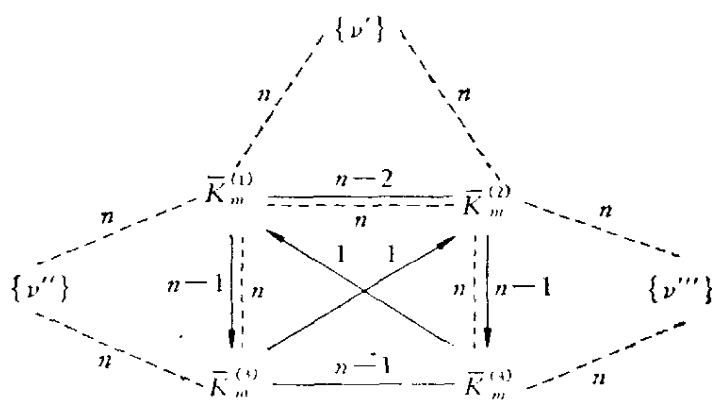

在后两种情形,一般说,有不止一个图可 以用所绘的图解来表示.

\section{参考资 料}

[1] Alavi, Y. \& Mitchem, J. Proc. of the First New York City Graph Theory Conference, 1-3, Springer-Verlag, 1971.

[2] Chartrand, G. \& Mitchem, J. ibid, 55-61.

本文 1975 年 5 月 10 日收到。 